Int. J. Dev. Biol. 58: 733-741 (2014)

doi: $10.1387 / \mathrm{ijdb} .140192 \mathrm{ag}$

\title{
Expression of aromatase in the embryonic brain of the olive ridley sea turtle (Lepidochelys olivacea), and the effect of bisphenol-A in sexually differentiated embryos
}

\author{
PATSY GÓMEZ-PICOS ${ }^{1}$, ITZEL SIFUENTES-ROMERO ${ }^{1}$, HORACIO MERCHANT-LARIOS ${ }^{2}$, \\ RUBÍ HERNÁNDEZ-CORNEJO' ${ }^{1}$, VERÓNICA DÍAZ-HERNÁNDEZ ${ }^{3}$ and ALEJANDRA GARCÍA-GASCA*,1 \\ ${ }^{1}$ Laboratory of Molecular Biology, Centro de Investigación en Alimentación y Desarrollo (CIAD), Mazatlán, Sinaloa, Mexico, \\ 2Instituto de Investigaciones Biomédicas, Universidad Nacional Autónoma de México, Mexico City, Mexico and \\ ${ }^{3}$ Departamento de Embriología, Facultad de Medicina, Universidad Nacional Autónoma de Mexico, Mexico City, Mexico
}

\begin{abstract}
Brain aromatase participates in several biological processes, such as regulation of the reproductive-endocrine axis, memory, stress, sexual differentiation of the nervous system, male sexual behavior, and brain repair. Here we report the isolation and expression of brain aromatase in olive ridley sea turtle (Lepidochelys olivacea) embryos incubated at male- and femalepromoting temperatures (MPT and FPT, respectively), at the thermosensitive period (TSP) and the sex-differentiated period. Also, aromatase expression was assessed in differentiated embryos exposed to bisphenol-A (BPA) during the TSP. BPA is a monomer of polycarbonate plastics and is considered an endocrine-disrupting compound. Normal aromatase expression was measured in both forebrain and hindbrain, showing higher expression levels in the forebrain of differentiated embryos at both incubation temperatures. Although no significant differences were detected in the hindbrain, expression was slightly higher at MPT. BPA did not affect aromatase expression neither in forebrains or hindbrains from embryos incubated at MPT, whereas at FPT an inverted U-shape curve was observed in forebrains with significant differences at lower concentrations, whereas in hindbrains a non-significant increment was observed at higher concentrations. Our data indicate that both incubation temperature and developmental stage are critical factors affecting aromatase expression in the forebrain. Because of the timing and location of aromatase expression in the brain, we suggest that brain aromatase may participate in the imprinting of sexual trends related to reproduction and sexual behavior at the onset of sex differentiation, and BPA exposure may impair aromatase function in the female forebrain.
\end{abstract}

KEY WORDS: aromatase, gene expression, Lepidochelys olivacea, temperature-dependent sex determination, bisphenol-A

\section{Introduction}

In vertebrates, sex is determined essentially by genetic and environmental factors. Many reptiles such as crocodilians, turtles and lizards display the latter mechanism, in which the temperature is the main factor acting on sex determination; therefore it is called temperature-dependent sex determination (TSD). In animals displaying TSD, the differentiation of the gonads into ovaries or testes depends on the incubation temperature of the eggs during a critical period of embryonic development known as the thermosensitive period (TSP).

Aromatase is a key enzyme responsible for the transformation of androgens into estrogens, and it has been demonstrated that these are involved in gonadal differentiation in non-mammalian vertebrates (Kuntz et al., 2004). Pieau and Dorizzi (2004) suggested that the gonads are the thermosensitive organ because they respond to temperature changes, and are the sites of expression and activity of aromatase. They also postulated that the incubation temperature during the TSP activates or represses the expression of the aromatase gene and that the production of estradiol is what

Abbreviations used in this paper: BPA, bisphenol-A; FPT, female-promoting temperature; MPT, male-promoting temperature; TSD, temperature-dependent sex determination; TSP, thermosensitive period.

\footnotetext{
*Address correspondence to: Alejandra García-Gasca. Laboratory of Molecular Biology, Centro de Investigación en Alimentación y Desarrollo (CIAD), Avenida Sábalo-Cerritos s/n, Mazatlán, Sinaloa 82010, Mexico.Tel.: +52-669-989-8700 (ext. 277). Fax: +52-669-989-8701. E-mail: alegar@ciad.mx
} 
determines the sex of the embryo.

On the other hand, Willingham et al. (2000) suggested that the brain is the organ that initially perceives the temperature signal promoting the activation of aromatase at the beginning of the TSP, and then the steroidogenic activity is transferred to the gonads. In a previous study it was demonstrated that the gonads are innervated during early stages of development in the olive ridley Lepidochelys olivacea (Merchant-Larios et al.,1989; Merchant-Larios and DíazHernández, 2013), implicating the direct participation of neural factors on gonadal development.

Aromatase is expressed in both gonads and brain, but it has also been found in many other tissues such as liver, adipose tissue, kidney, digestive tract, skin and placenta (Simpson et al., 2002). Brain aromatase has been implicated in several physiological and behavioral processes such as regulation of the reproductiveendocrine axis, memory and stress, sexual differentiation of the nervous system, male sexual behavior, and brain repair (Balthazart and Ball, 1998; García-Segura et al., 1999). Fluctuations in brain aromatase activity may play an important role in the regulation of aggressive and social behavior. Some experimental studies suggest that brain aromatase activity also impacts cognitive function (García-Segura, 2008).

Neuronal metabolism of testosterone, particularly the synthesis of estradiol by aromatase, is important for male sexual behavior in many vertebrates. In the green anole lizard (Anolis curvieri), estradiol facilitates female receptivity and increases sexual motivation in males, suggesting that, as in other vertebrates, aromatization of androgens into estrogens in the brain may be important for the control of sex-specific reproductive behaviors (Cohen and Wade, 2011). Despite expression and activity of aromatase have been documented in the brain of reptiles, little is known about its distribution within this organ, especially in regions that control sexual behavior.

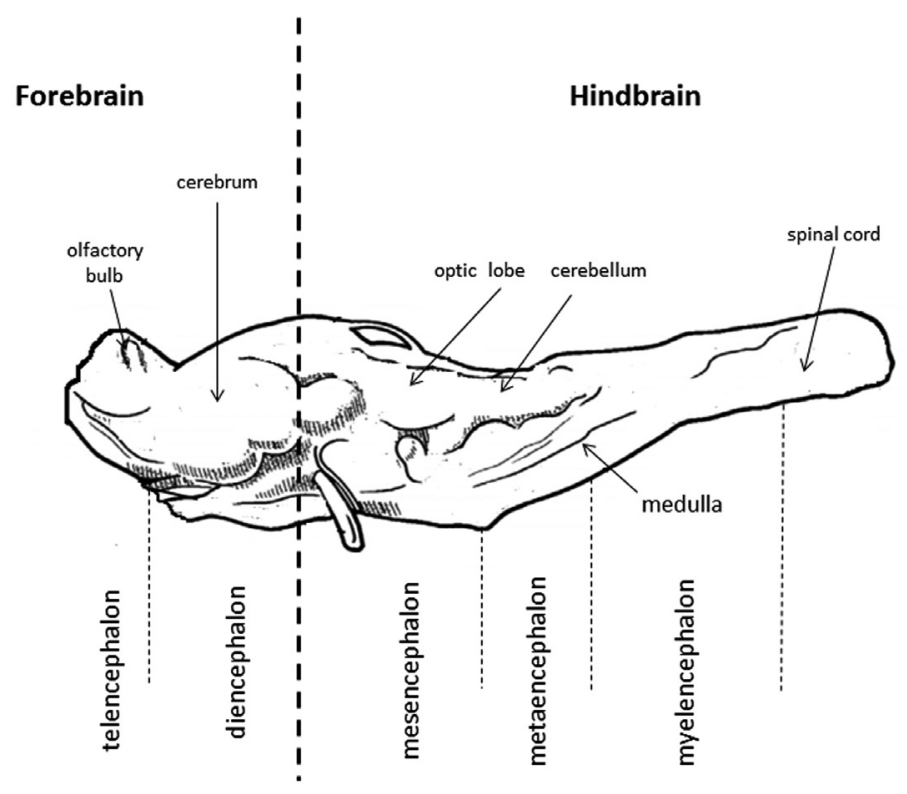

Fig. 1. Schematic representation of the sea turtle brain ladapted from Wyneken, 2001). The dashed line indicates the limit between forebrain and hindbrain.
In the brain of vertebrates, aromatase has been mainly localized in anterior brain areas related to reproduction control and sexual behavior (Lephart, 1996; Balthazart and Ball, 1998). Aromatase is expressed in the developing brain of alligators, leopard geckos, and red-eared slider turtles, and both activity and mRNA appear to be sexually monomorphic in these species (Milnes et al., 2002; Endo et al., 2008; Willingham et al., 2000). Nevertheless, in diamondback terrapin it was found that the brain-specific transcript is expressed at higher levels at the beginning of the TSP in embryos incubated at FPT than at MPT. Aromatase expression in the male brain is low at the beginning of the TSP, but it becomes higher than in the female brain in the second half of the TSP (Jeyasuria and Place, 1998). Furthermore, brain aromatase activity has been shown to be sexually dimorphic in some mammals (Lephart, 1996), teleost fish, and the Japanese quail, in which males display higher activity than females in brain areas related to reproduction (Aste et al., 1998; Balthazart et al., 1990; González and Piferrer, 2002).

Bisphenol A (BPA) was first synthesized in 1891, and has been shown to act as a xenoestrogen since 1936 (von Saal et al., 2007; Wolstenholme et al., 2011). Final products in which BPA is used include food and beverage plastic storage and heating containers, dental fillings and sealants and the interior lacquer-coating of food cans, among others (Brotons et al., 1994, Olea et al., 1996; Biles et al., 1997).

Effects of BPA exposure have been well documented, especially in mammalian model systems including effects on the male and female reproductive tract, immune system, metabolism and growth, and development of preneoplastic and neoplastic lesions of the mammary gland and the mammary gland's response to carcinogens (Vanderberg et al., 2013).

In the brain, early exposures to BPA can lead to permanent changes in brain morphology, disruptions in behavior, and alterations in learning, memory, exploration, and emotional responsiveness (Wolstenholme et al., 2011). Furthermore, BPA effects in the reproductive tract and the brain have been reported in nonmammalian systems, for instance, zebrafish embryos exposed to BPA presented high levels of brain P450aromB mRNA (Kishida et al., 2001; Chung et al., 2011), which could result in an abnormal estrogen production affecting the developing central nervous system and sexual behavior.

It has also been shown that in ovo exposure to BPA in the crocodilian Caiman latirostris causes sex reversal. When eggs were exposed to BPA during the critical time of sex determination, all resultant offspring were females regardless of the incubation temperature (Stoker et al., 2003).

Regarding wildlife exposure effects, several studies have found endocrine disruption specially in the reproductive tract including alteration of sex determination and gonadal function from exposure both during and after gonadal organogenesis; induction of vitellogenin expression in males and juveniles, and other indicators of reproductive success such as reduction in spermatogenesis (for a review on BPA effects in wildlife see Crain et al., 2007). To our knowledge, BPA effects in the brain have not been documented in wildlife.

Our goal was to investigate whether aromatase transcription in the brain is temperature-dependent, if the brain isoform is differentially expressed in anterior and posterior brain regions (Fig. 1) during development, and the potential effects of BPA exposure in the expression of aromatase at both incubation temperatures 
and brain regions.

This study reports the isolation and expression of a brain aromatase transcript from olive ridley (L. olivacea) embryos incubated at MPT and FPT at the undifferentiated period (stage 24) and the differentiated period (stage 26-27). Aromatase expression was also analyzed in differentiated embryos exposed to BPA during the TSP.

\section{Results and Discussion}

\section{Isolation of the brain aromatase transcript}

The aromatase full coding sequence was isolated from the brain, and consisted of 1614 nucleotides (GenBank: KF411436), and showed $99 \%$ similarity with its gonad counterpart (GenBank: KF268021) and 98\% similarity with aromatase from Trachemys scripta (GenBank: AF178949) and Chrysemys picta (GenBank: DQ383800).

The aromatase gene in L. olivacea contains nine exons as in humans. In the sea turtle, brain and gonad aromatase isoforms show almost the same coding sequence, except for point variations in few nucleotides. An alignment of $L$. olivacea brain and gonad aromatase amino acid sequences was performed using the ClustalW2 (EBI) (http://www.ebi.ac.uk/Tools/msa/clustalw2/) software (Fig. 2).

According to Murdock and Wibbels (2003), five functional domains (I- V) of aromatase have been found in the turtle T. scripta, as well as in other vertebrates such as alligator, chicken, bovine, human, frog, and tilapia. L. olivacea aromatase isoforms contained the functional domains characteristic of vertebrate aromatase molecules: I) membrane-spanning domain, II) helical domain, III) Ozols peptide domain, IV) aromatic domain, and V) heme-binding domain (Fig. 2). These functional domains (mainly domains IV and V) show high homology among vertebrate aromatase sequences (Murdock and Wibbels, 2003).

\section{Aromatase expression in the brain}

Expression differences between incubation temperatures and developmental stages

In forebrains, significant differences in expression levels were detected $(P=0.001)$. The groups presenting statistical significant differences were: differentiated female (DF) vs undifferentiated female (UF) ( $P=0.002)$, differentiated female (DF) vs undifferentiated male (UM) $(P=0.013)$, and differentiated male (DM) vs undifferentiated female (UF) $(P=0.042)$ (Fig. 3A). Hindbrains presented lower levels of expression, and did not show significant differences between groups (Fig. 3B).

A two-way ANOVA revealed that variation in aromatase gene expression in the forebrain was due to the developmental stage $(\mathrm{P}<0.001)$, and that temperature was the factor affecting variation in gene expression in the hindbrain $(\mathrm{P}=0.006)$. Considering the whole brain, temperature was the main factor affecting aromatase expression $(P=0.048)$, and the interaction between temperature and developmental stage was not significant $(P=0.989)$.

The brain (unlike the gonad) does not undergo a complete morphological differentiation as develop-
LoAromGonad IoArombrain

LoAromGonad LoAromBrain

IoAromGonad LoAromBrain

IoAromGonad LoAromBrain

LoAromGonad LoAromBrain

LoAromGonad LoAromBrain

LoAromGonad LoAromBrain

LoAromGonad LoAromBrain

LoAromGonad LoAromBrain ment progresses from the beginning to the end of the TSP. Nevertheless it is a sensorial organ and perceives environmental changes which in turn are transmitted to other organs through signaling events. For this reason, it is not surprising that temperature is the main factor affecting aromatase gene expression in the whole brain, and, because of the sex-related functions of the forebrain, it is also not surprising that both factors (temperature and developmental stage) affect aromatase expression in this region.

Research in T. scripta, Chelydra serpentina, and Malaclemys terrapin revealed that aromatase transcripts are found in the brains of embryos incubated at both temperatures, before and after the TSP, but they are more abundant at the beginning of this period in putative females. Moreover, the incubation temperature affects aromatase expression in the brain of $M$. terrapin, before differences become apparent in the gonads (Jeyasuria and Place, 1998). Later in embryogenesis, during the TSP, the levels of aromatase expression in the brains of putative males overcome expression levels of putative females, while aromatase in the gonads of putative females increases exponentially (Jeyasuria and Place, 1998; Place et al., 2001; Ramsey and Crews, 2007).

These observations are not in complete agreement with the results obtained in the present study for $L$. olivacea, as both males and females at stage 27 (differentiated period) presented higher expression levels of brain aromatase, therefore the increase of expression levels are not limited to males. Nevertheless we divided the brain to measure gene expression, and the main site of aromatase expression was the forebrain. Results could vary when using the whole brain. Also, growth and development in freshwater MIIETLNLMHYNITRVVPEVMPTATVPIIIIMCFI FIIWNYEETSIPGPGFCMGIGPIIS 60

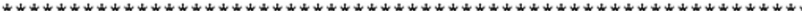

HGRFLWMGVGNACNYYNKMYGEFMRVWISGEETLIISKSSSIFHVMRHGQYISRFGSKLG 120 HGRFLWMGVGNACNYYNRMYGEFMRVWISGEETIIISRSSSIFHVMRHGOYISRFGSRIG 120

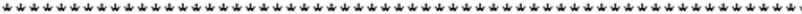

IQCIGMNENGIIFNNNPALWREIRPFFTKALSGPGLVRMIAICVESTKDHLDRLEDVTAG 180 LQCIGMHENGI I FNNNPALWREIRPFFTRAISGPGLVRMIAICVESTRDHIDRLEDVTAG 180 से

IGNINVLNFMRQITLDASNTLFLGIPLDENAIVLRIQNYFDAWQTLILRPDIFFRISWLY 240 LGNINVLNFMRQITLDASNTLFLGIPLDENAIVLRIQNYFDAWQTLILRPDIFFRISWLY 240

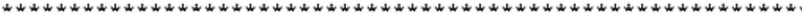
II RKYEKSARDLKEAIEILIEQRRQRLSTVERLEDHMDFASQLIFAQSRGDLTGENVNQCVI 300 KKYEKSARDLKEAIEILIEQRRQRLSTVERLEDHMDFASQLIFAQSRGDLTGENVNQCVL 300

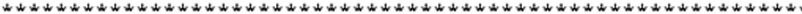
III EMMIAAPDTISVTLFFMLVLIAEHPKVEEDMMKEIQAIIGDRDVQSNDMSNLKVVENFIN 360 EMMIAAPDTLSVTIFFMLVLIAEHPKVEEDMMREIQAIIGDRDVQSNDMSNLKVVENFIN 360

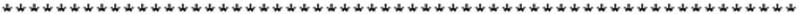
IV

ESMRYQPVVDIVMRKALQDDVIDGYPVRRGTNIIINIGRMHKLEFFPRPSEFSLKNFERN 420 ESMRYQPVVDIVMRRAIQDDVIDGYPVRRGTNIILNIGRMHKLEFFPRPNEFSIRNFERN 420 से $\mathrm{V}$

VPSRYFQPFGFGPRGCVGKFIAMVMMRAILVTLIRRYRVQTPKGRGLNNIQRSNDLSMHP 480 VPSRYFQPFGFGPRGCVGKFIAMVMMRAILVTFLRRYRVQTPRGRGLNNIQRSNDLSMHP 480

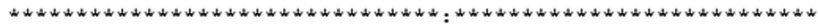

NERQPELEMFLMPRRNIDKCQDD 503 NERQPFLEMFLMPRRNIDKCQDD 503

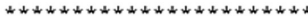

MILETLNLMHYNITRVVPEVMPTATVPILLIMCFLFLIWNYEETSIPGPGFCMGIGPIS 60

Fig. 2.Amino acid sequences of $L$. olivacea gonad (LoAromGonad) and brain (LoAromBrain) aromatase isoforms. Aromatase gene domains are represented from I to $\mathrm{V}$ : I, membrane spanning region; II, helical region; III, Ozols peptide region; IV, aromatic domain; and $V$, heme-binding domain (adapted from Murdock and Wibbels, 2003). 
turtles is faster than in sea turtles.

Previous studies point to the brain as a site of steroid hormone synthesis in response to temperature. Salame-Mendez etal., (1998) measured E2 in the diencephalon/mesencephalon and telencephaIon in L. olivacea demonstrating differences between incubation temperatures during the TSP. They found that the concentration of E2 was higher in the diencephalon/mesencephalon of putative females than in putative males during the TSP. These results agree with present findings, since higher aromatase expression in the female's forebrain was observed at the end of the TSP, although no significant differences were found between sexes $(P=0.331)$.

Among reptiles, aromatase is expressed in the developing brain of alligators, leopard geckos, and turtles, and both expression and activity in the whole brain is apparently monomorphic (Endo et al., 2008; Milnes et al., 2002; Crews et al., 2001; Cohen and Wade, 2012). For instance, in Alligator mississippiensis, the brain was divided in forebrain, hypothalamus, and hindbrain, and the highest aromatase expression was located in the hypothalamus at both male and female-promoting temperatures. There were no significant differences in aromatase expression in the brain between MPT and FPT, or between developmental stages (Gabriel et al., 2001). These observations agree with present findings, since the results in $L$. olivacea suggest that expression of brain aromatase is monomorphic, showing higher expression levels in the forebrain.

Brain aromatase is also present during development of many other species such as Japanese quail (Coturnix japonica) (Schumacher and Balthazart, 1986; Aste et al., 1998), mice and rats, in

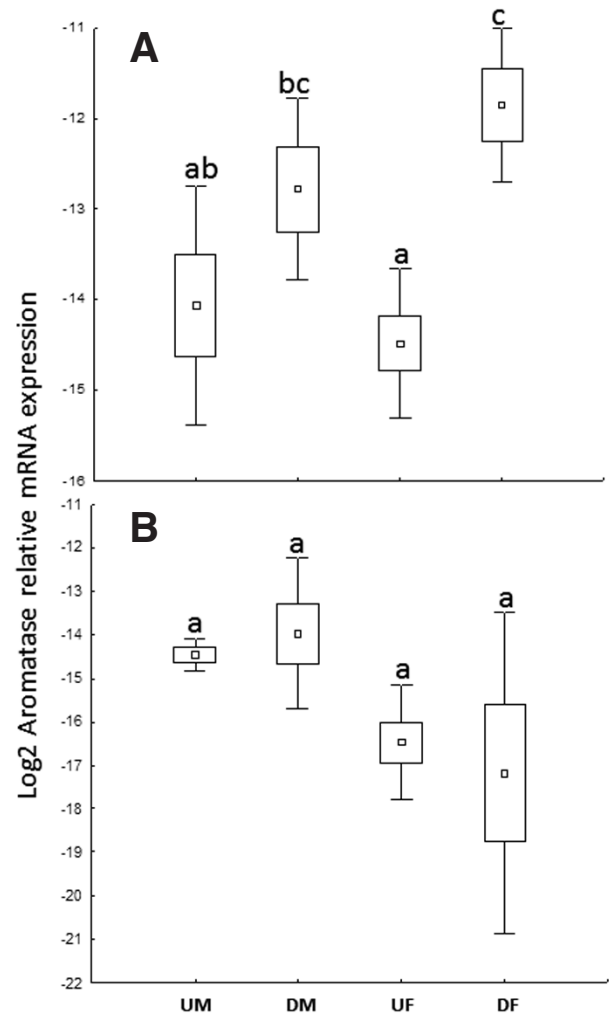

Fig. 3. Normal aromatase expression in forebrain (A) and hindbrain (B) of turtle embryos. UM, undifferentiated at MPT- stage 24; DM, differentiated at MPT- stage 27; UF, undifferentiated at FPT- stage 24; DF, differentiated at FPT-stage 27. Expression levels were normalized with log (base 2). Different letters indicate significant differences in expression levels. which expression in the hypothalamus is higher in males than in females (Hutchison et al., 1994). In sexually mature organisms, as in quails, immunohistochemistry and in situ hybridization studies have revealed that aromatase is specifically expressed in the dimorphic preoptic nucleus, showing higher expression in males (Schumacher and Balthazart, 1986; Aste et al., 1998; Balthazart et al., 1990; Foidart et al., 1995; Voigt et al., 2007), in which the activation of the copulatory behavior is controlled by an estrogenandrogen synergism, therefore, the action of testosterone along with aromatase and $5 \alpha$ - reductase is necessary and sufficient for the activation of the male sexual behavior (Panzica et al., 1996). Similar results have been found in rats (Roselli et al., 1996).

Interestingly, in quail it has been demonstrated that sex differences in aromatase activity are not associated to expression levels. For instance, mRNA levels in the brain have been found to be higher in females than in males (Voigt et al., 2007), but males have shown higher aromatase activity than females (Balthazart et al., 2009). These results are consistent with previous studies in rats, where males show higher expression levels than females, but activity does not differ between sexes (Wagner and Morrell, 1996; 1997). Research in crocodiles indicates that there are no significant differences in aromatase expression levels between sexes or developmental stages, but an increase in enzymatic activity was observed during the TSP in both sexes, with higher enzymatic activity in putative females at stage 24 (Milnes et al., 2002). These results indicate that mRNA expression is not always consistent to enzymatic activity. According to Voigt et al. (2011), these sex differences in enzymatic activity are probably the result of post-translational events. Possibly, these mechanisms modulate the activity of brain aromatase in quail without affecting mRNA and protein concentration. However, previous studies with $M$. terrapin demonstrated that the transcription of aromatase mRNA was consistent with enzymatic activity (Jeyasuria et al., 1994; 1995; Jeyasuria and Place, 1998).

In teleost fish, research has revealed that aromatase expression and activity are detected in the brain, especially in forebrain (Forlano et al., 2006). While semi-quantitative RT-PCR has shown that expression of CYP19A2 was significantly higher in anterior brain areas in males; in posterior brain areas no differences were detected between sexes. In L. olivacea we found that the expression of aromatase occurs at lower levels in the brain than in the gonad (data not shown), nevertheless, like in fish, higher expression was found in the forebrain of sexually differentiated organisms (stage 27, Fig. 3A).

Whether the brain or gonad initially perceives the temperature signal is still unclear. Merchant-Larios et al. (1989) found innervation in the gonads during early stages of development in L. olivacea. This observation suggests that neural factors might mediate the influence of temperature in sex determination. Later, Willingham et al. (2000) supported this theory suggesting that the brain is the thermosensitive organ which initially perceives the temperature signal, promoting the activation of aromatase at the beginning of the TSP and then steroidogenic activity is transferred to the gonads. Epigenetic mechanisms might be involved in tissue-specific aromatase gene expression, since the environment often influences developmental gene expression by altering the epigenetic status in regulatory regions. Unraveling regulatory mechanisms in species displaying TSD will help to understand how the environment regulates gene expression during sex determination and differentiation. 


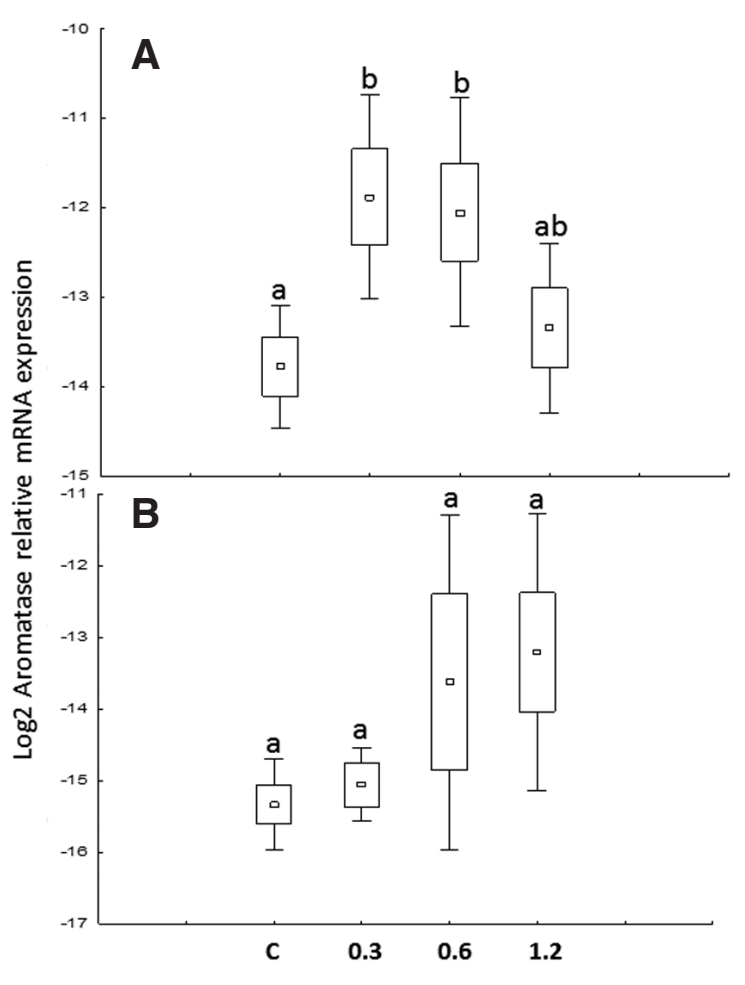

Fig. 4. Aromatase expression in the forebrain (A) and hindbrain (B) of bisphenol-A (BPA)-exposed embryos at female-promoting temperature-stage 26. $C$, ethanol control; $0.3,0.6$, and 1.2 indicate BPA concentrations in $\mathrm{mg}$ per egg. Expression levels were normalized with log (base 2). Different letters indicate significant differences in expression levels.

Since aromatase in the olive ridley's forebrain is expressed at lower levels during early stages of development (stage 24), increasing at later stages (stage 27), coinciding with the differentiation of the gonad into ovary, we suggest a forebrain-gonad communication system which may be related to sex differentiation.

\section{Expression of brain aromatase in BPA-exposed embryos}

Diverse environmental chemicals present endocrine disrupting activity by virtue of their ability to bind nuclear estrogen/androgen receptors (ER and $A R$ respectively) or to mimic or block their biological responses; therefore these chemicals are known as endocrine-disrupting compounds (EDCs). Results obtained from BPA exposure experiments are consistent with previous studies showing that BPA induces expression of aromatase in the brain (Chung et al., 2011). Recent work has revealed that BPA can lead to adverse effects in brain morphology and behavior (Chung et al., 2011).

In L. Olivacea, aromatase expression showed an inverted Ushape curve in BPA-exposed female forebrains, in which lower concentrations of BPA (0.3 and $0.6 \mathrm{mg}$ per egg) were able to significantly induce aromatase expression $(P=0.015$ and $P=0.02$ respectively), whereas the highest concentration (1.2 mg per egg) did not show significant differences when compared to control animals ( $\mathrm{P}=0.546)$ (Fig. 4A). This behavior is known as non-monotonic dose-response curve (NMDRC) in which the dose-response relationship is not linear; it has been observed in both in vitro and in vivo BPA exposure experiments, in which lower doses induce significant differences in endpoints compared to controls, and higher doses do not (Vandenberg, et al., 2013). Several mechanisms have been identified that demonstrate how hormones and EDCs produce nonmonotonic responses in cells, tissues, and animals (for a review of NMDRC to EDCs see Vandenberg et al., 2012). The simplest mechanism for NMDRCs explains that hormones can be acutely toxic at high doses but still elicit a response at low, physiologically relevant doses. Therefore, experiments working at concentrations that are cytotoxic are incapable of detecting responses that are mediated by ligand-binding interactions (Vandenberg et al., 2012).

NMDRCs may also occur due to differences in receptor affinity at low versus high doses, for instance, at low doses, BPA almost exclusively binds to the estrogen receptor (ER, including the membrane-bound ER or mER), but at high doses it can also bind other hormone receptors, such as the androgen receptor (AR) (Vandenberg et al., 2012). It has been shown that androgens regulate the expression of aromatase in the preoptic area and medial basal hypothalamus of adult rats (Abdelgadir et al., 1994) and in the pituitary of the ricefield eel (Zhanga et al., 2012). Interestingly, BPA acts as an AR antagonist, blocking the action of androgens (Wolstenholme et al., 2011). This antagonist effect of BPA could likely explain the aromatase down-regulation at the highest concentrations in L. olivacea's forebrain, resulting in NMDRC. It is also well known that several hormones control or influence their own secretion using a feedback system, in this regard, it is also possible that the decreased expression of aromatase in the female forebrain at higher concentrations of BPA is the result of a negative feedback in the regulation of aromatase by estrogens.

In the female hindbrain, BPA exposure resulted in an increment of aromatase expression at higher concentrations; however, this increment was not significant $(P=0.15)$ due probably to high individual variability (Fig. 4B). In the male brain, BPA did not produce any significant effect in the expression of aromatase $(P=0.705$ and $P=0.876$ for forebrain and hindbrain respectively), although individual variability was also high (Fig. 5).

Altogether, our results indicate that in the olive ridley, aromatase is expressed in the whole brain, showing higher expression levels in the forebrain, as in other vertebrates. Apparently, BPA exposure affects aromatase expression in the female forebrain of sexually differentiated embryos in a non-monotonic fashion, but expression does not seem to be significantly affected in the brain of male embryos. This sex-specific expression of aromatase may be due to the sex-specific differences of endogenous estrogens, since in females estrogenic effects from BPA may synergize with the production of endogenous estrogens (in gonads and brain), significantly increasing aromatase expression in the brain at lower concentrations of BPA, and then decreasing expression levels at higher concentrations as a negative feedback because of estrogen overproduction. In males, overall estrogen production is lower than in females; therefore, BPA did not show significant effects in aromatase expression, nevertheless individual variability was high, meaning that some embryos were more responsive than others.

Several studies have revealed that exposure to BPA disrupts development and reproduction in females, for instance, BPA affects ovulation in the female brown trout (Donaldson et al., 1983), and estrous cycles in mammalian females (Porrini et al., 2005; Rubin et al., 2001). Kubo et al. (2003) reported that in rats, the exposure to a low dose of BPA during a critical period of development (fetal and suckling), disrupts the normal sexual behavior without any ef- 
fect in the reproductive system. A different study revealed that like estrogen, BPA induces brain-specific expression of aromatase in early zebrafish embryos (Chung et al., 2011). Zebrafish contains two aromatase genes due to genomic duplication during teleost evolution, $A r O A$ and $A r o B$, expressed in the ovary and the brain respectively. The $A r O A$ gene is not induced by estrogen, whereas the $A r o B$ gene contains an estrogen-responsive element (ERE) (Boon et al., 2010; Chung et al., 2011). Other studies revealed that $A r o B$ is strongly expressed in the telencephalon, hypothalamus and preoptic areas, and that estrogen increases the levels of brain aromatase in these regions (Menuet el al., 2005; Lassiter et al., 2007). Interestingly, in mammalian (Lephart, 1996) and avian (Steimer and Hutchinson, 1981) brains, aromatase expression is also enhanced by estradiol (Boon et al., 2010), but the mechanism by which estrogen regulates aromatase expression is still elusive since no EREs have been found in promoter regions. It is thought that epigenetic modifications might regulate this event (Kumar et al., 2009). BPA may affect the epigenetic status of a gene altering its expression patterns either by increasing the expression of histones (Zhu et al., 2009) or by changing the methylation status of cytosines (Dolinoy et al., 2007) although the exact mechanism through which BPA affects epigenetically the expression of a gene is still unclear. Whether the brain aromatase gene from $L$. olivacea contains EREs or androgen-responsive elements (AREs) in the promoter region, or is epigeneticallyregulated has to be investigated.

\section{Conclusions}

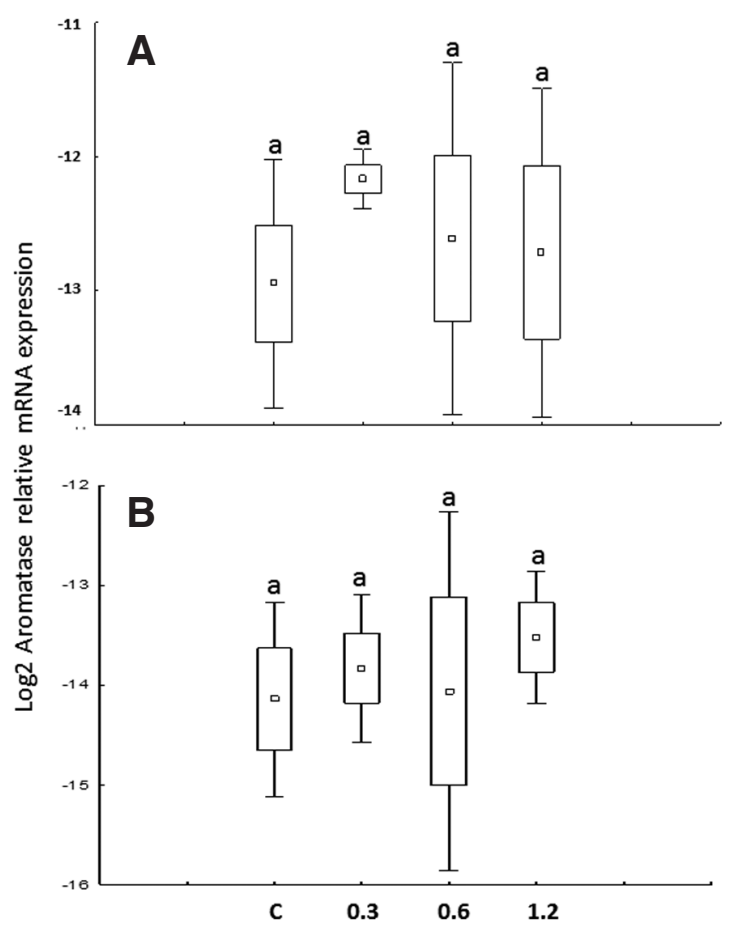

Fig. 5. Aromatase expression in the forebrain (A) and hindbrain (B) of BPA-exposed embryos at MPT-stage 26. $C$, ethanol control; $0.3,0.6$, and 1.2 indicate BPA concentrations in $\mathrm{mg}$ per egg. Expression levels were normalized with log (base 2). Different letters indicate significant differences in expression levels.
In the olive ridley sea turtle, brain aromatase is expressed in the brain, showing higher expression levels in the forebrain. The incubation temperature seemed to be the main factor affecting aromatase gene expression in the whole brain; nevertheless, the developmental stage also influences aromatase expression in the forebrain.

We suggest the existence of a forebrain-gonad communication system, in which production of estrogen increases (by aromatase activity) in male and female forebrains at the end of the TSP, coinciding with an increase of estrogen production in the female gonad and subsequent differentiation of the innervated ovary. Both incubation temperature and developmental stage are critical factors affecting aromatase expression in the forebrain. Since higher expression levels were detected in differentiated embryos, estrogen production in the embryonic forebrain may participate in the imprinting of sexual trends related to reproduction and sexual behavior at the onset of sex differentiation, time in which BPA exposure may impair aromatase function, particularly in female embryos.

\section{Materials and Methods}

\section{Animals}

Freshly laid eggs were obtained from La Escobilla beach (96 $27^{\prime} 16^{\prime \prime} \mathrm{W}$, $15^{\circ} 40^{\prime} 36^{\prime \prime} \mathrm{N}$ ), Oaxaca, Mexico. 30 eggs were placed in covered plastic containers filled with moistened vermiculite into incubators at either $26^{\circ} \mathrm{C}$ (MPT) or $33^{\circ} \mathrm{C}(\mathrm{FPT})$ and few were periodically dissected to determine the degree of development. Temperature in both incubators was recorded every two hours with LogTag (www.datalogger.com.mx). For normal aromatase expression assays, brains of embryos corresponding to stage 24 (gonads morphologically undifferentiated) and stage 27 (gonads morphologically differentiated as ovary or testis) at both temperatures were obtained by microdissection.

It has been documented that $6-12 \mu \mathrm{g}$ of $17 \beta$-estradiol (E2) per egg affect sex differentiation in L. olivacea (Merchant-Larios et al., 1997). Since BPA is considered a weak xenoestrogen (Witorsch, 2002; Wolstenholme et al., 2011), we chose three doses of BPA to perform exposure experiments: $1.2 \mathrm{mg}$ per egg (100 times more concentrated than the highest E2 dose exerting an effect on L. olivacea), and two lower doses ( 0.6 and $0.3 \mathrm{mg}$ per egg). Once the eggs entered the TSP (stages 23 and 24 for MPT and FPT respectively), they were subjected to a topical treatment with BPA using ethanol as vehicle. Ethanol alone was used as control.

Five to eight embryos incubated at both temperatures and the three concentrations of BPA were sampled at stage 26. All brains were divided into anterior (forebrain) and posterior (hindbrain) regions (Fig. 1) for expression analyses.

\section{Cloning of $\mathrm{L}$. olivacea brain aromatase transcript}

Brain samples were taken from stage 27 embryos incubated at male- and female-promoting temperatures. After dissection, tissues were preserved in RNAlater (Ambion, UNIPARTS, Mexico) and stored at $-20^{\circ} \mathrm{C}$ until use. Total RNA was isolated using Trizol reagent (Invitrogen, Accesolab, Mexico) according to the manufacturer's instructions, followed by a double digestion with DNase I to eliminate genomic DNA contamination. Reverse transcription was performed at $42^{\circ} \mathrm{C}$ using M-MLV RT (Promega, UNIPARTS, Mexico) and random primers. Reactions using RNAinstead of CDNA were performed to confirm genomic DNA elimination.

Degenerate PCR primers (Arom-F: 5'-TTG GCA TGM ATG AAAATG G and Arom-R: 5'-CAT YAC CAT GGC DAT RWA YTT YCC) were designed from conserved regions of aromatase transcripts obtained from previously reported sequences in GenBank: Xenopus laevis (AB031278.1), Rana pipiens (DQ449025.1), Trachemys scripta (AF178949.1), Alligator mississippiensis (AY029233.1), and Chrysemys picta (FJ195593.1). PCR was performed using a high fidelity Taq polymerase (Advantage, Clontech, 
UNIPARTS, Mexico), PCR conditions were: one cycle at $94^{\circ} \mathrm{C} 1 \mathrm{~min} ; 40$ cycles at $94^{\circ} \mathrm{C} 1 \mathrm{~min}, 48^{\circ} \mathrm{C} 1 \mathrm{~min}$, and $68^{\circ} \mathrm{C} 1.5 \mathrm{~min}$, and a final cycle at $68^{\circ} \mathrm{C}$ for $10 \mathrm{~min}$, rendering a product of $\sim 850 \mathrm{bp}$.

PCR fragments were ligated into a pGEM-T vector (Promega, UNIPARTS, Mexico) using T4 ligase according to manufacturer's protocol. Transformation was performed with Escherichia coliDH5 $\alpha$ competent cells (Invitrogen, Accesolab, Mexico). Positive clones were sequenced in Macrogen, Inc (South Korea). Sequences were manually edited using BioEdit and submitted to BLAST (Basic Local Alignment Search Tool) from NCBI (National Center for Biotechnology Information). Once the identity of this partial sequence was confirmed as aromatase, two new sets of primers were designed to obtain a larger sequence to the 5' and 3' ends (Arom5-F: 5'-GAT GAT ACT GGA AAC CCT GAA TC; Arom5-R: 5'-TCT TTC CAG AGT GCT GGG TT, and Arom3-F: 5'- CAT TCT GAA CAT TGG ACG TAT G; Arom3-R: 5'-AGA GTA TGC GTG ACA GCA CCT A, respectively). PCR was performed with Taq polymerase (Promega, UNIPARTS, Mexico) under the following conditions: one cycle at $94^{\circ} \mathrm{C}$ for $2 \mathrm{~min}$, and 40 cycles at $94^{\circ} \mathrm{C} 1 \mathrm{~min}, 54^{\circ} \mathrm{C} 1 \mathrm{~min}, 72^{\circ} \mathrm{C}$ $1 \mathrm{~min}$, rendering products of $\sim 400 \mathrm{bp}$, which complemented the previous fragment producing the full coding sequence. Ligation, transformation, and sequencing were performed as above.

\section{Real-time PCR}

Gene-specific primers (Lo-Arom-F: 5'-TGG TCA TGC GCA AGG CTT TA and Lo-Arom-R: 5'-GGC CAAATC CAAATG GCT GA) were designed to perform real-time PCR using a CFX96 thermal cycler (Bio-Rad, Mexico) and Eva Green ${ }^{\circledR}$ Supermix 2X (Bio-Rad, Mexico). Five to nine individual samples per developmental stage and incubation temperature were analyzed in triplicate. Relative gene expression in brains was obtained through the $\triangle C T$ method (Livak and Schmittgen, 2001), using the geometric mean of two internal control genes, which proved to be equally stable according to Llera-Herrera et al., (2012): 18S rRNA (Forward: 5'-CAC GGC CGG TAC AGT GA; Reverse: 5'-CCG GGT TGG TTT TGG TCT GA) and $\beta$ actin (Forward: 5'-ACA CAG GTG TGT AAG ATG GCT TTG G; Reverse: 5'-GAA GAC TCA GGT CCA GGA AAG GAA A) in order to normalize the aromatase raw $C T$ data $(\triangle C T)$ (Vandesompele et al., 2002). PCR conditions were as follows: one cycle at $95^{\circ} \mathrm{C}$ for $30 \mathrm{~s} ; 40$ cycles at $95^{\circ} \mathrm{C} 20 \mathrm{~s}$, $60^{\circ} \mathrm{C} 20 \mathrm{~s}$. PCR specificity was confirmed through melting curve analysis.

\section{Statistical analysis}

$\Delta C T$ values were converted to their linear form using the $2-\Delta C T$ equation (Livak and Schmittgen, 2001). Gene expression results were log-transformed in order to reach normality and variance equality. One and two way ANOVAs coupled to the Holm-Sidak test for multiple comparisons were performed using SigmaPlot v11 and STATISTICA v7 in order to find statistical differences in aromatase relative expression levels $(P<0.05)$. Normalized data ( $\log 2)$ were plotted according to Yamamoto et al., (2013).

\section{Acknowledgments}

The authors would like to thank Martha Harfush, Cuauhtémoc Peña Flores and Elpidio López for assistance in collecting L. olivacea nests; to DGVS-SEMARNAT for capture permits; to Alberto Abreu, Bruno GómezGil and Ravi Sangha for their constructive comments to this work; and to Alejandro Marmolejo for technical assistance. We also thank CIAD and CONACYT (Mexico) and PAPIIT-UNAM (IN205213-2) for the financial support granted to PGP and HML.

\section{References}

ABDELGADIR, S.E., RESKO, J.A., OJEDA, S.R, LEPHART, E.D, MCPHAUL, M.J. and ROSELLI, C.E. (1994). Androgens regulate aromatase cytochrome P450 messenger ribonucleic acid in rat brain. Mol Cell Endocrinol 135(1) DOI: http:// dx.doi.org/10.1210/endo.135.1.8013375.

ASTE, N., PANZICA, G.C., VIGLIETTI-PANZICA, C., HARADA, N. and BALTHAZART, J. (1998). Distribution and effects of testosterone on aromatase mRNA in the quail forebrain: a non-radioactive in situ hybridization study. J Chem Neuroanat
14: 103-115.

BALTHAZART, J. and BALL, G. (1998). New insights into the regulation and function of brain estrogen synthase (aromatase). Trends Neurosci 21: 243-249.

BALTHAZART, J., CORNIL, C.A., CHARLIER, T.D., TAZIAUX, M. and BALL, G.F. (2009). Estradiol, a key endocrine signal in the sexual differentiation and activation of reproductive behavior in quail. J Exp Zool A Ecol Genet Physiol 311: 323-345.

BALTHAZART, J., SCHUMACHER, M. and EVRARD, L. (1990). Sex differences and steroid control of testosterone-metabolizing enzyme activity in the quail brain. $J$ Neuroendocrinol 2: 675-683.

BILES, J.E., MCNEAL, T.P., BEGLEY, T.H. and HOLLIFIELD, H.C. (1997). Determination of Bisphenol-A in reusable polycarbonate food-contact plastics and migration to food simulating liquids. J Agric Food Chem 45: 3541-3544

BOON, W.C., CHOW, J.D.Y. and SIMPSON, E.R. (2010). The multiple roles of estrogens and the enzyme aromatase. Prog Brain Res 181: 209-232.

BROTONS, J.A., OLEA-SERRANO, M.F., VILLALOBOS, M. and OLEA, N. (1994) Xenoestrogens released from lacquer coating in food cans. Environ Health Perspect 103: 608-612.

CHUNG, E., GENCO, M.C., MEGRELIS, L. and RUDERMAN, J.V. (2011). Effects of bisphenol $A$ and triclocarban on brain-specific expression of aromatase in early zebrafish embryos. Proc Natl Acad Sci USA 43: 17732-17737.

COHEN, R.E. and WADE J. (2012). Expression of aromatase and two isozymes of $5 a-474$ reductase in the developing green anole forebrain. $J$ Neuroendocrinol 24: $1213-1221$.

COHEN, R.E. and WADE, J. (2011). Aromatase mRNA in the Brain of Adult Green Anole Lizards: Effects of Sex and Season. J Neuroendocrinol 23: 254-260.

CRAIN, D.A., ERIKSEN, M., IGUCHI, T., JOBLING, S., LAUFER, H., LEBLANC, G.A. and GUILLETTE L.J. (2007). An ecological assessment of bisphenol-A: Evidence from comparative biology. Reprod Toxicol 24: 225-239.

CREWS, D., FLEMING, A., WILLINGHAM, E., BALDWIN, R. and SKIPPER, J.K. (2001). Role of steroidogenic factor I and aromatase in temperature-dependent sex determination in the red-eared slider turtle. J Exp Zool 290: 597-606.

DOLINOY, D.C., HUANG, D. and JIRTLE, R.L. (2007). Maternal nutrient supplementation counteracts bisphenol A-induced DNA hypomethylation in early development Proc Natl Acad Sci USA 32:13056-13061.

DONALDSON, E.D. and HUNTER, G.A. (1983). Induced final maturation, ovulation, and spermiation in cultured fish. Fish Physioly 9 (Part B): 351-404.

ENDO, D., KANAHO, Y.I. and PARK, M.K. (2008). Expression of sex steroid hormone related genes in the embryo of the leopard gecko. Gen Comp Endocrinol 155: 70-49178.

FOIDART, A., REID, J., ABSIL, P., YOSHIMURA, N., HARADA, N. and BALTHAZART, J. (1995). Critical re- examination of the distribution of aromatase-immunoreactive cells in the quail forebrain using antibodies raised against human placental aromatase and against the recombinant quail, mouse or human enzyme. J Chem Neuroanat 8: 267-282.

FORLANO, P.M., SCHLINGER, B.A. and BASS, A.H. (2006). Brain aromatase: new lessons from non- mammalian vertebrate systems. Front Neuroendocrinol 27: 247-499 74 .

GABRIEL, W.N., BLUMBERG, B., SUTTON, S., PLACE, A.R. and LANCE, V.A. (2001) Alligator aromatase cDNA sequence and its Expression in embryos at male and female incubation temperatures. J Exp Zool 290: 439-448.

GARCÍA-SEGURA, L., WOZNIAK, A., AZCOITIA, I., RODRIGUEZ, J., HUTCHISON, R. and HUTCHISON, J. (1999). Aromatase expression by astrocytes after brain injury: implications for local estrogen formation in brain repair. Neuroscience 89: 567-578.

GARCÍA-SEGURA., L.M. (2008). Aromatase in the brain, not just for reproduction anymore. J Neuroendocrinol 20: 705-712.

GONZÁLEZ, A. and PIFERRER F. (2002). Characterization of aromatase activity in the sea bass: effects of temperature and different catalytic properties of brain and ovarian homogenates and microsomes. J Exp Zool 293: 500-510.

GRADDY, L.G., KOWALSKI, A.A., SIMMEN, F.A., DAVIS, S.L., BAUMGARTNER, W.W and SIMMEN, R.C. (2000). Multiple isoforms of porcine aromatase are encoded by three distinct genes, J Steroid Biochem Mol Biol 73: 49-57.

HUTCHISON, J.B., BEYER, C., GREEN, S. and WOZNIAK, A. (1994). Brain formation of oestrogen in the mouse: sex dimorphism in aromatase development. J Steroid Biochem Mol Biol 49: 407-415. 
IWABUCHI, J., WAKO, S., TANAKA, T., ISHIKAWA, A., YOSHIDA, Y. and MIYATA, S. (2007). Analysis of the p450 aromatase gene expression in the Xenopus brain and gonad. J Steroid Biochem Mol Biol 107: 149-155.

JEYASURIA, P. and PLACE, A.R. (1998). Embryonic brain-gonadal axis in temperature-522 dependent sex determination of reptiles: a role for $\mathrm{p} 450$ aromatase (CYP19). J Exp Zool 281: 428-449.

JEYASURIA, P., PLACE, A.R., LANCE, V.A. and BLUMBERG, B. (1995). The role of p450 aromatase in temperature-dependent sex determination in reptiles. $J$ Cell Biochem Suppl 19B: 51.

JEYASURIA, P., ROOSENBURG, W.M. and PLACE, A.R. (1994). Role of P-450 aromatase in sex determination of the diamondback terrapin, Malaclemys terrapin. J Exp Zool 270: 95-111.

KISHIDA, M, MCLELLAN M, MIRANDA J.A. and CALLARD G.V. (2001). Estrogen and xenoestrogens upregulate the brain aromatase isoform (P450aromB) and perturb markers of early development in zebrafish (Danio rerio). Comp Biochem Physiol B 129: 261-268.

KUBO, K., ARAI, O., OMURA, M., WATANABE, R., OGATA, R. and AOU, S. (2003). Low dose effects of bisphenol $A$ on sexual differentiation of the brain and behavior in rats. Neurosci Res 45: 345- 356.

KUMAR, P., KAMAT, A. and MENDELSON, C. R. (2009). Estrogen receptor alpha (ERalpha) mediates stimulatory effects of estrogen on aromatase (CYP19) gene expression in human placenta. J Mol Endocrinol 23: 784-793.

KUNTZ, S., CHESNEL, A., FLAMENT, S. and CHARDARD, D. (2004). Cerebral and gonadal aromatase expressions are differently affected during sex differentiation of Pleurodeles waltl. J Mol Endocrinol 3: 717-727.

LASSITER, C.S. and LINNEY, E. (2007). Embryonic expression and steroid regulation of brain aromatase cyp19a1b in zebrafish (Danio rerio). Zebrafish 4: 49-57.

LEPHART, E.D. (1996). A review of brain aromatase cytochrome P450. Brain Res Rev 22: 1-26.

LIVAK, K.J. and SCHMITTGEN, T.D. (2001). Analysis of relative gene expression data using real-time quantitative PCR and the 2- $\triangle C T$ method. Methods 25: 402-408.

LLERA-HERRERA, R., GARCíA- GASCA, A., HUVET, A. and IBARRA, A.M. (2012). Identification of a tubulin- $\alpha$ gene specifically expressed in testis and adductor muscle during stable reference gene selection in the hermaphrodite gonad of the lion's paw scallop Nodipecten subnodosus. Marine Genomics 6: 33-44.

MATSUMOTO, Y. and CREWS, D. (2012). Molecular mechanisms of temperature-554 dependent sex determination in the context of ecological developmental biology. Mol Cell Endocrinol 354: 103-110.

MENUET, A., PELLEGRINI, E., BRION, F., GUEGUEN, M.M., ANGLADE, I., PAKDEL, F. and KAH, O. (2005). Expression and estrogen-dependent regulation of the zebrafish brain aromatase gene. J Comp Neurol 485: 304-320.

MERCHANT-LARIOS, H. and DÍAZ-HERNÁNDEZ, V. (2013). Environmental sex determination mechanisms in reptiles. Sex Dev 7: 95-103.

MERCHANT-LARIOS, H., RUIZ-RAMÍREZ, S., MORENO-MENDOZA, N. and MARMOLEJO-VALENCIA, A. (1997). Correlation among thermosensitive period, estradiol response, and gonad differentiation in the sea turtle Lepidochelys olivacea. Gen Comp Endocrinol 107: 373-385.

MERCHANT-LARIOS, H., VILLALPANDO, I. and CENTENO, B. (1989). Gonadal morphogenesis under controlled temperature in the sea turtle Lepidochelys olivacea. Herpetol Monogr 3: 43-61.

MILNES, M.R., ROBERTS, R.N. and GUILLETTE, L.J. (2002). Effects of incubation temperature and estrogen exposure on aromatase activity in the brain and gonads of embryonic alligators. Environ Health Perspect 110: 393-396.

MURDOCK, C. and WIBBELS, T. (2003). Cloning and expression of aromatase in a turtle with temperature-dependent sex determination. Gen Comp Endocrinol 130: 109-573 119.

NATIONAL ACADEMY OF SCIENCES. 1999. Hormonally Active Agents in the Environment. National Academy Press. Washington, DC, USA. p. Available from http://www.nap.edu/catalog/6029.html

OLEA, N., PULGAR, R., PEREZ, P., OLEA-SERRANO, F., RIVAS, A., NOVILLO-578 FERTRELL, A., PEDRAZA, V., SOTO, A.M. and SONNENSCHEIN, C. (1996). Estrogenicity of resin-based composites and sealants used in dentistry. Environ Health Perspect 104: 298-305.

PANZICA, G.C., VIGLIETTI-PANZICA, C. and BALTHAZART, J. (1996). The sexually dimorphic medial preoptic nucleus of quail: a key brain area mediating steroid action on male sexual behavior. Front Neuroendocrinol 17: 1-75.
PIEAU, C. and DORIZZI, M. (2004). Oestrogens and temperature-dependent sex determination in reptiles: all is in the gonads. $J$ Endocrinol 181: 367-377.

PIEAU, C., DORIZZI, M., RICHARD-MERCIER, N. and DESVAGES, G. (1998). Sexual differentiation of gonads as a function of temperature in the turtle Emys orbicularis: Endocrine function, intersexuality and growth. J Exp Zoo/281:400-408.

PLACE, A. R., LANG, J., GAVASSO, S. and JEYASURIA, P. (2001). Expression of P450arom in Malaclemys terrapin and Chelydra serpentina: A tale of two sites. $J$ Exp Zool 290: 673-690.

PORRINI, S., BELLONI, V., DELLA, S.D. FARABOLLINI, F., GIANNELLI, G. and DESSI-FULGHERI, F. (2005). Early exposure to a low dose of bisphenol A affects socio-sexual behavior of juvenile female rats. Brain Res Bull 65: 261-266.

RAMSEY, M. and CREWS, D. (2007). Adrenal-kidney-gonad complex measurements may not predict gonad-specific changes in gene expression patterns during temperature-dependent sex determination in the red-eared slider turtle (Trachemys scripta elegans). J Exp Zool 307A: 463-470.

ROSELLI, C.E., KLOSTERMAN, S.A. and FASASI, T.A. (1996). Sex differences in androgen responsiveness in the rat brain: regional differences in the induction of aromatase activity. Neuroendocrinology 64: 139-145.

RUBIN, B.S., MURRAY, M.K., DAMASSA, D.A., KING, J.C. and SOTO, A.M. (2001) Perinatal exposure to low doses of bisphenol $\mathrm{A}$ affects body weight, patterns of estrous cyclicity, and plasma LH levels. Environ Health Perspect 109: 675-680.

SALAME-MÉNDEZ, HERRERA-MUÑOZ, A., J., MORENO-MENDOZA, N. and MERCHANT-LARIOS, H. (1998). Response of diencephalon but not the gonad to female-promoting temperature with elevated estradiol levels in the sea turtle Lepidochelys olivacea. J Exp Zool 280: 304-313.

SCHUMACHER, M. and BALTHAZART, J. (1986). Testosterone-induced brain aromatase is sexually dimorphic. Brain Res 370: 285-293.

SIMPSON, E., CLYNE, C., RUBIN, G., BOON, W., ROBERTSON, K., BRITT, K. SPEED, C. and JONES, M. (2002). Aromatase- A brief overview. Annu Rev Physiol 64: 93-127.

STEIMER, T. and HUTCHISON, J.B. (1981). Androgen increases formation of behaviourally effective oestrogen in dove brain. Nature 292: 345-347.

STOKER, C., REY F., RODRIGUEZ H., RAMOS J.G., SIROSKY P., LARRIERA A., LUQUE, E.H. and MUÑOZ-DE-TOROA, M. (2003). Sex reversal effects on Caiman latirostris exposed to environmentally relevant doses of the xenoestrogen bisphenol A. Gen Comp Endocrinol 133: 287-296.

VANDENBERG, L.N., COLBORN, T., HAYES, T.B., HEINDEL, J.J., JACOBS, D.R., LEE, D., SHIODA, T., SOTO, A.M., VOM SAAL, F.S., WELSHONS, W.V., ZOELLER, R.T. and MYERS, J.P. (2012). Low-Dose Hormones and Endocrine-623 Disrupting Chemicals: Low-Dose Effects and Nonmonotonic Dose Responses. Endocrine Reviews 33: 1-78.

VANDENBERG, L.N., EHRLICH, S., BELCHER, S., BEN-JONATHAN, N., DOLINOY, D.C., HUGO, E.R., HUNT, P.A., NEWBOLD, R.R., RUBIN, B.S., SAILI, K.S., SOTO, A.M., WANG, H.S. and VOM SAAL, F.S. (2013). Low dose effects of bispheno A. An integrated review of in vitro, laboratory animal, and epidemiology studies. Endocrine disruptors 1: e25078.

VANDESOMPELE, J., DE PRETER, K., PATTYN, F., POPPE, B., VAN ROY, N. DE PAEPE, A. and SPELEMAN, F. (2002). Accurate normalization of real-time quantitative RT-PCR data by geometric averaging of multiple internal control genes. Genome Biol 3: 1-11.

VOIGT, C., BALL, G.F. and BALTHAZART, J. (2007). Neuroanatomical specificity of sex differences in expression of aromatase mRNA in the quail brain. $J$ Chem Neuroanat 33: 75-86.

VOIGT, C., BALL, G.F. and BALTHAZART, J. (2011). Effects of sex steroids on aromatase mRNA expression in the male and female quail brain. Gen Comp Endocrinol170: 180-188.

VOM SAAL, F.S., AKINGBEMI, B.T., BELCHER, S.M., BIRNBAUM, L.S., CRAIN, D.A. ERIKSEN, M., FARABOLLINI, F., GUILLETTE, L.J. JR., HAUSER, R., HEINDEL, J.J.et al. (2007). Chapel Hill bisphenol A expert panel consensus statement: integration of mechanisms, effects in animals and potential to impact human health at current levels of exposure. Reprod Toxicol 24:131-138.

WAGNER, C.K. and MORRELL, J.I. (1996). Distribution and steroid hormone regulation of aromatase mRNA expression in the forebrain of adult male and female rats: a cellular-level analysis using in situ hybridization. J Comp Neurol 370: 71-84.

WAGNER, C.K. and MORRELL, J.I. (1997). Neuroanatomical distribution of aromatase mRNA in the rat brain: indications of regional regulation. $J$ Steroid Biochem 
Mol Biol 61: 307-314.

WILLINGHAM, E., BALDWIN, R., SKIPPER, J.K. and CREWS, D. (2000). Aromatase activity during embryogenesis in the brain and adrenal-kidney-gonad of the red660 eared slider turtle, a species with temperature-dependent sex determination. Gen Comp Endocrinol 119: 202-207.

WOLSTENHOLME, J.T., RISSMANA, E.F. and CONNELLY, J.J. (2011). The role of Bisphenol A in shaping the brain, epigenome and behavior. Horm Behav 59: 296-305.

WYNEKEN, J. (2001). The Anatomy of Sea Turtles. U.S. Department of Commerce NOAA Technical Memorandum NMFS-SEFSC-470, pp.125- 145.
YAMAMOTO, M., SINGH, A., SAVA, F., PUI, M., TEBBUTT, S.J. and CARLSTEN, C. (2013). MicroRNAexpression in response to controlled exposure to diesel exhaust: Attenuation by the antioxidant $\mathrm{N}$-Acetylcysteine in a randomized crossover study. Environ Health Perspect 121: 670-675.

ZHANGA, Y., ZHANGA, S., ZHOUA, W., YEC, X., GED, W., CHENGE, C.H.K., LINA H., ZHANGA, W. and ZHANGA, L. (2012). Androgen rather than estrogen up-673 regulates brain-type cytochrome $\mathrm{P} 450$ aromatase (cyp19a1b) gene via tissue-674 specific promoters in the hermaphrodite teleost ricefield eel Monopterus albus. Mol Cell Endocrinol 1: 125-135.

ZHU, Z., EDWARDS, R.J. and BOOBIS, A.R. (2009). Increased expression of histone proteins during estrogen-mediated cell proliferation. Environ Health Perspect 678: 928-934. 


\section{Further Related Reading, published previously in the Int. J. Dev. Biol.}

Sexual dimorphism of AMH, DMRT1 and RSPO1 localization in the developing gonads of six anuran species

Rafal P. Piprek, Anna Pecio, Katarzyna Laskowska-Kaszub,Jacek Z. Kubiak and Jacek M. Szymura

Int. J. Dev. Biol. (2013) 57: 891-895

Dual embryonic origin of the hyobranchial apparatus in the Mexican axolotl (Ambystoma mexicanum)

Asya Davidian and Yegor Malashichev

Int. J. Dev. Biol. (2013) 57: 821-828

Clonal analyses in the anterior pre-placodal region: implications for the early lineage bias of placodal progenitors

Sujata Bhattacharyya and Marianne E. Bronner

Int. J. Dev. Biol. (2013) 57: 753-757

Amphibian interorder nuclear transfer embryos reveal conserved embryonic gene transcription, but deficient DNA replication or chromosome segregation

Patrick Narbonne and John B. Gurdon

Int. J. Dev. Biol. (2012) 56: 975-986

Origins of $\mathrm{Cdx} 1$ regulatory elements suggest roles in vertebrate evolution

Stephen J. Gaunt and Yu-Lee Paul

Int. J. Dev. Biol. (2011) 55: 93-98

Reptile scale paradigm: Evo-Devo, pattern formation and regeneration

Cheng Chang, Ping Wu, Ruth E. Baker, Philip K. Maini, Lorenzo Alibardi and Cheng-Ming Chuong

Int. J. Dev. Biol. (2009) 53: 813-826

Proteomics analysis of regenerating amphibian limbs: changes during the onset of regeneration

Michael W. King, Anton W. Neff and Anthony L. Mescher

Int. J. Dev. Biol. (2009) 53: 955-969

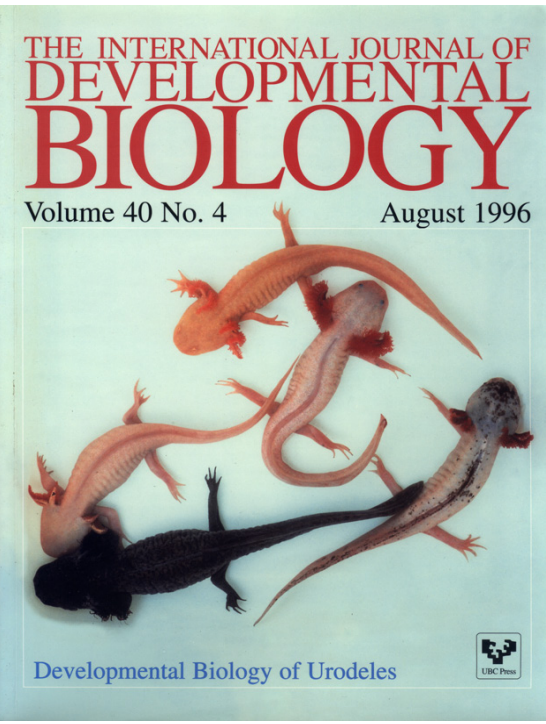

5 yr ISI Impact Factor $(2013)=2.879$
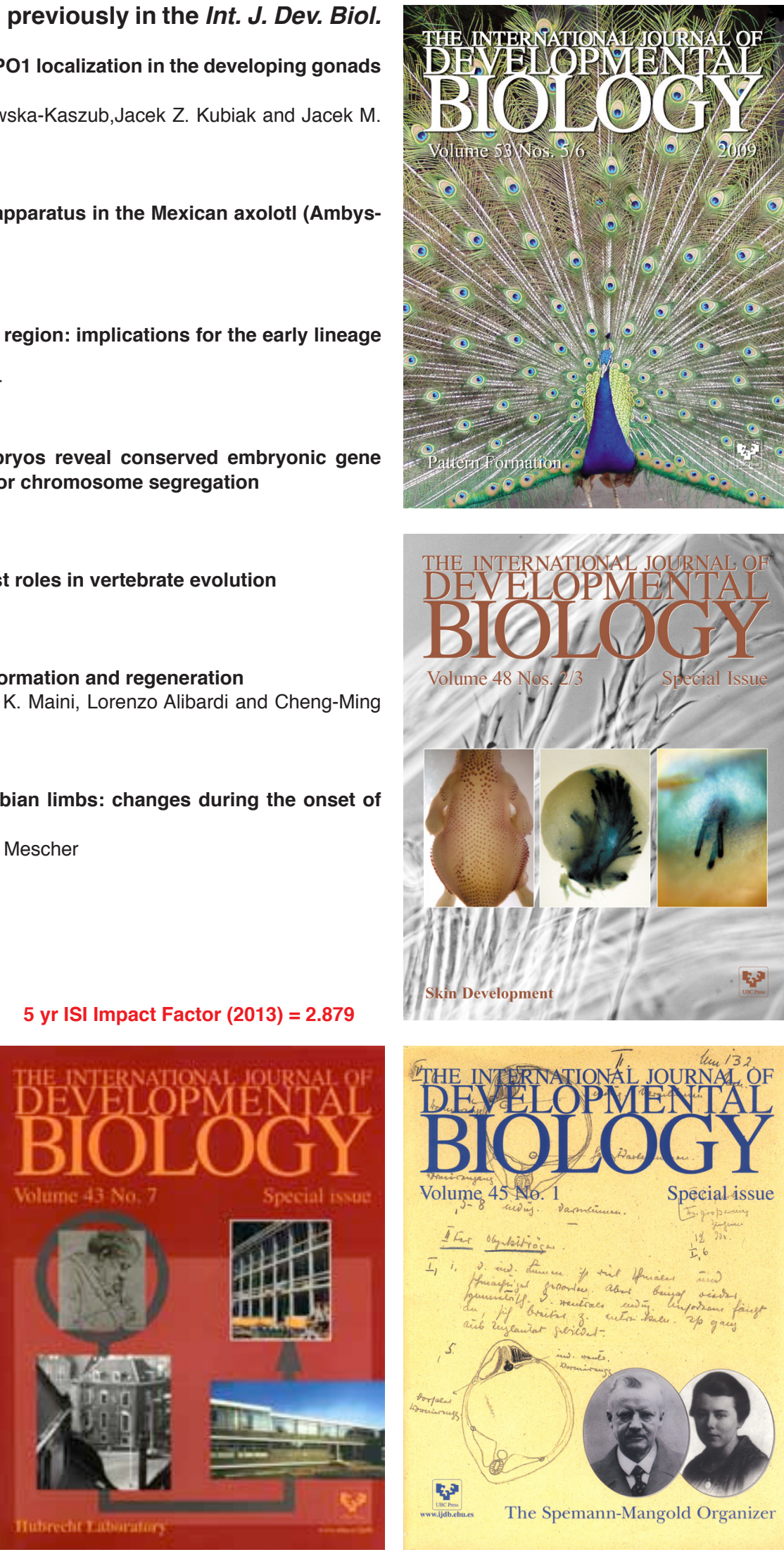

Volume 45 No. 1

Special-issue

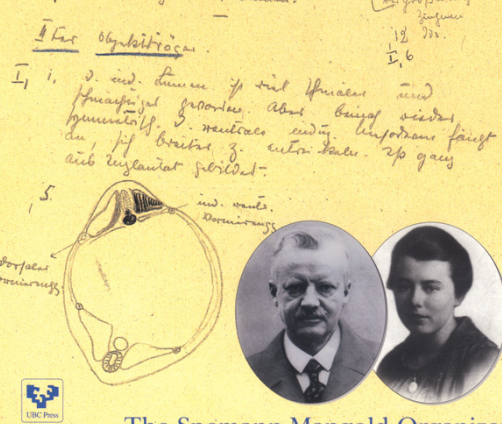

The Spemann-Mangold Organizer 